Dept. of Animal Medicine,

Fac. Vet. Medicine, Kafr El-Sheikh, Tanta Univ.

\title{
CLINICAL AND THERAPEUTICAL STUDIES ON DERMATOPHILOSIS ON SOME FARM ANIMALS
}

(With One Table and 12 Figures)

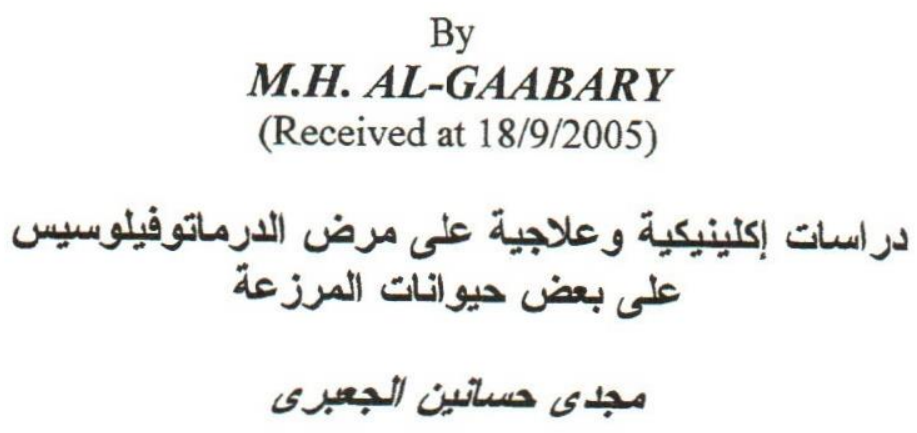

يعد مرض الدرماتوفيلوسيس واحدأ من الأمر اض المعدية التى تصيب مغظم أنو اع اع الحيوانات

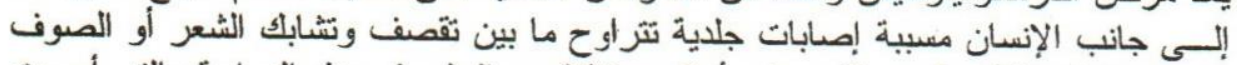

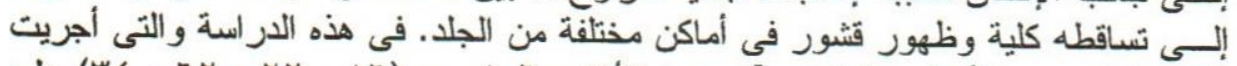

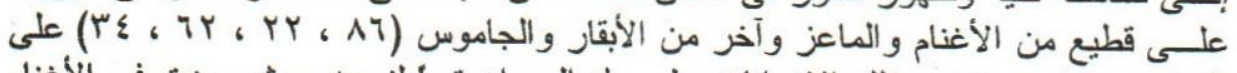

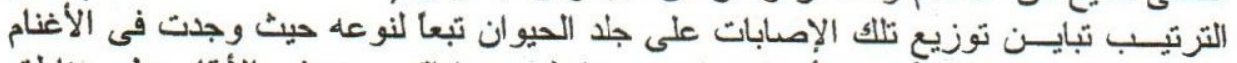

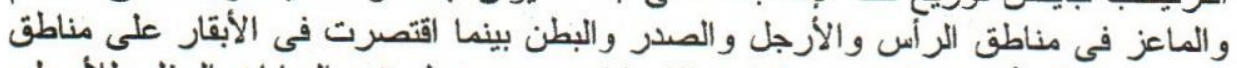

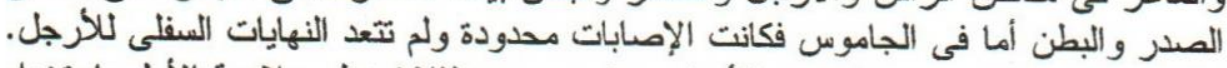

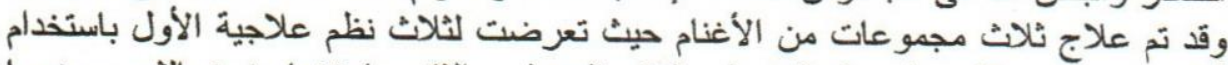

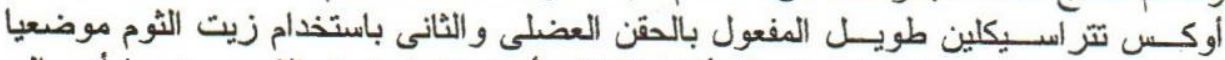

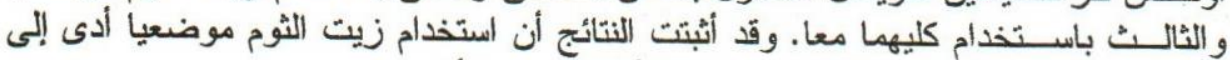
معدلات شفاء كاملة وسريعة ودون ارنداد للأعر اض مرة ألخت أخرى.

\section{SUMMARY}

Dermatophilosis is a bacterial disease affecting wide range of animal species in addition to humans. The clinical picture of the disease was studied in a flock of sheep and goats ( 86 and 22 respectively) and herd of cattle and buffaloes (62 and 34 respectively). The clinical picture was in the form of skin lesions which varied in its severity and distribution owing to species affected. In sheep, the lesions were in the form of irregular area of alopecia with crust formation in the face, ears and legs from the coronet to the knees. Matted, broken or easily detached wool is recorded. The lesions were similar in goats while in cattle the lesions were distributed on the skin of chest and abdomen. In buffaloes it was 
confined on the distal portion of the legs. Out of the diseased sheep, 18 were classified into 3 groups each of six animals. The first group were treated parentrally using long acting oxytetracycline. Those of the second group were treated topically using garlic oil. The $3^{\text {rd }}$ group was treated both parentally and topically. It was noticed that garlic oil is highly efficient in treatment of dermatophilosis.

Key words: Animal dermatophilosis, Diagnosis of dermatophilosis, Treatment of dermatophilosis

\section{INTRODUCTION}

Dermatophilosis is an enzootic bacterial disease affecting most animal species in addition to humans, particularly those working with livestock (Dean et al., 1961 and yeruham et al., 1991). It may be acute or chronic, partial or progressive exudative dermatitis with subsequent formation of scabs under which the hair or fleece tends to break or be matted together (Hagan and Burner, 1992; Zaria, 1993; Higgins and Write, 1998).

The disease leads to considerable swelling and pain in the affected areas. It may resolve spontaneously or fatal under certain conditions (Sutherland et al., 1991). There is a number of predisposing factors facilitating the infection; Nutritional stress, mechanical trauma to the skin, moisture or rainfall and ectoparasites being at the fore front of these factors (Elisah, 2004) Treatment of dermatophilosis remains a matter of great concern regarding the recurrence of signs as well as the difficulties to cure it using antibiotic by parentral route. On the other side many topical treatment had been tried with variable curative effects Ethanol extracts of leaves of Senna alata, Lantana camera and Mitracarpus scaber were used as topical ointment once daily for 6-15 days resulting in complete healing within 3-4 weeks without recurrence for 3 years (Ali - Emmanuel et al., 2003). Some essential oils (lavander, thymos and garlic were investigated invitro in comparison with povidone iodine. It was demonstrated that garlic oil is the most effective one (Elisah, 2004).

This study aimed to declare the clinical features of dermatophilosis in different animal species.and evaluation of garlic oil as a topical treatment in some diseased animals. 


\section{MATERIALS and METHODS}

\section{Animals:}

The animals that investigated in this study at Gharbia Governorate belonged to sheep flock consisted of 86 sheep and 22 goats of different ages and dairy herd consisting of 62 cattle and 34 buffaloes, Some of which were suffering from skin lesions in the form of matted hair or wool, formatrom of scabs and crusts, erythema and exudative dermatitis. It was suspected to be dermatophilosis. The diseased animals were subjected to clinical examination according to Kelly (1984).

\section{Bactreiology:}

Swabbing of the under crust lesions was made and used for both direct microscopy as well as culture on blood agar media aerobically for 48- 72 hs. according to Quin et al. (1994).

\section{Treatment:}

Out of the diseased sheep, 18 were allocated into 3 groups each of six animals. The first group were treated parentrally with long acting oxytetracycline the widely used antibiotic in treatment of dermatophilosis (Ilemobad et al., 1979; Abedl - Halim et al., 2000 and Ammar, 2003) with a dose rate of $20 \mathrm{mglkg}$. intramuscularly. Animals of the 2 nd group were treated topically with garlic oil which was used for the first time in this purpose depending on its high invitro efficiency (Elisah 2004). It was applied daily for 8 successive days. Those of the $3^{\text {rd }}$ group were subjected to both parentral treatment with long acting oxytetracycline and topical application of garlic oil. The treated animals were kept under clinical observation weekly and bacteriological examination every 2 weeks for 6 weeks.

\section{RESULTS}

The clinical examination revealed that the clinical picture varied in its severity and distribution of the lesions owing to the species affected. The lesions in sheep appeared on the head region as irregular area of alopecia covered with crusts specially on the edges of ears and the face. It may involve the skin allover the body in the form of moisten lesions under which the wool is broken or matted and easily detached leaving row surface which is erythematous in nature. The legs also were effected specially the carpal region. Goats showed similar lesions while in cows, the lesions were restricted on the skin of chest and abdomen. In buffaloes the lesions were confined on the distal portion of the legs (Fig $1-12)$. 
Assiut Vet. Med. J. Vol. 51 No. 107 October 2005
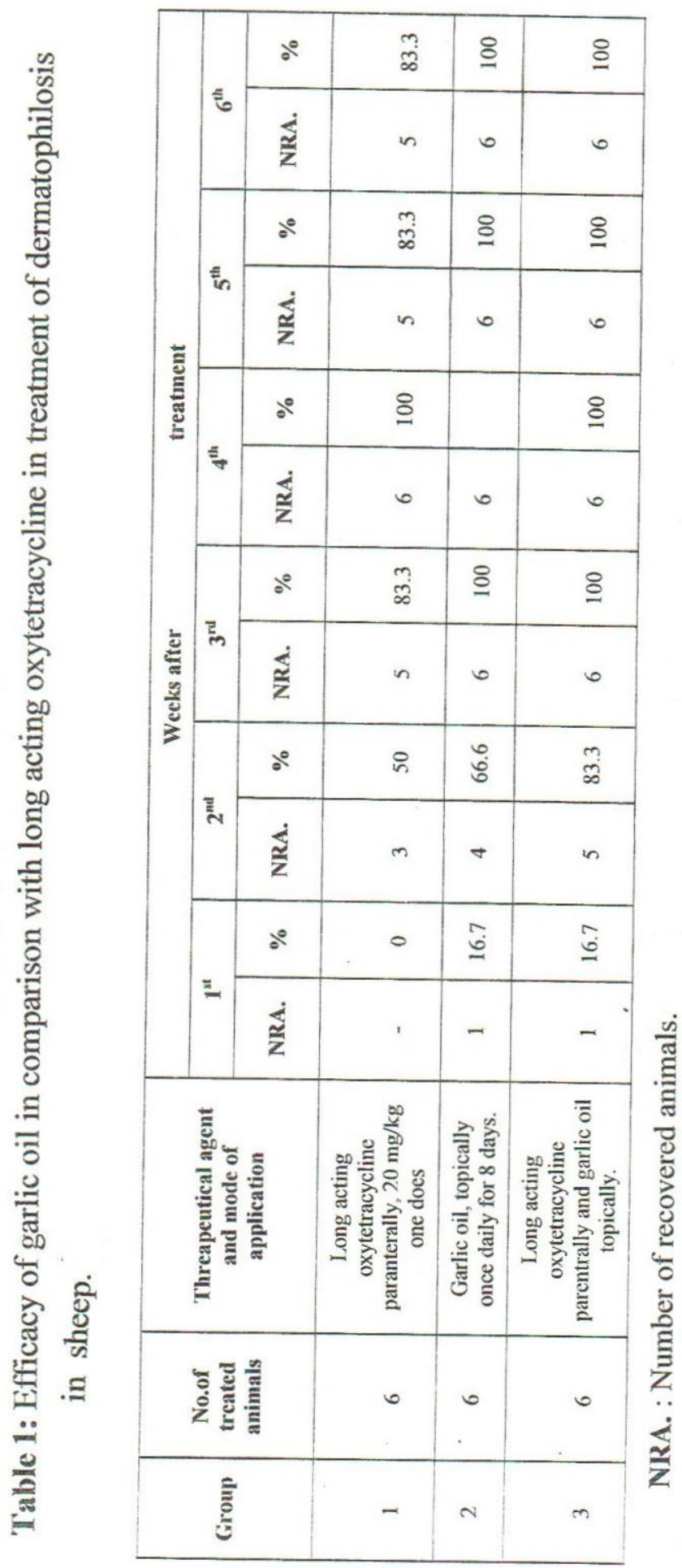
Regarding the treatment trials, all treated animals showed complete clinical and bacteriological cure at the end of the $4^{\text {th }}$ week. In the $1^{\text {st }}$ group the recovery was started at the end of $2^{\text {nd }}$ week with recovery rate of $50 \%$ which elevated to be $83.3 \%$ at the end of $3^{\text {rd }}$ week and $100 \%$ at the end of the $4^{\text {th }}$ week. recurrence of the disease had been recorded at the end of the $5^{\text {th }}$ week. In the other 2 groups, the recovery commenced at the end of $1^{\text {st }}$ week with a rate of $16.7 \%$ reaching $100 \%$ at the end of $3^{\text {rd }}$ week. Without any evidence of recurrence Table (1).

The application of garlic oil on the lesion of the diseased sheep softened the crusty lesion. The crusts started falling off from the lesions after the $4^{\text {th }}$ day after treatment. The falling off was rapid and progressive. It fall off completely within 8-10 days. The growth of the wool was observed at $12^{\text {th }}$ day post application and the treated animals appeared normal within 4-5 weeks.

Fig. 1: A lamb suffering from dermatophilosis showing skin lesions in the form of area of alopecia

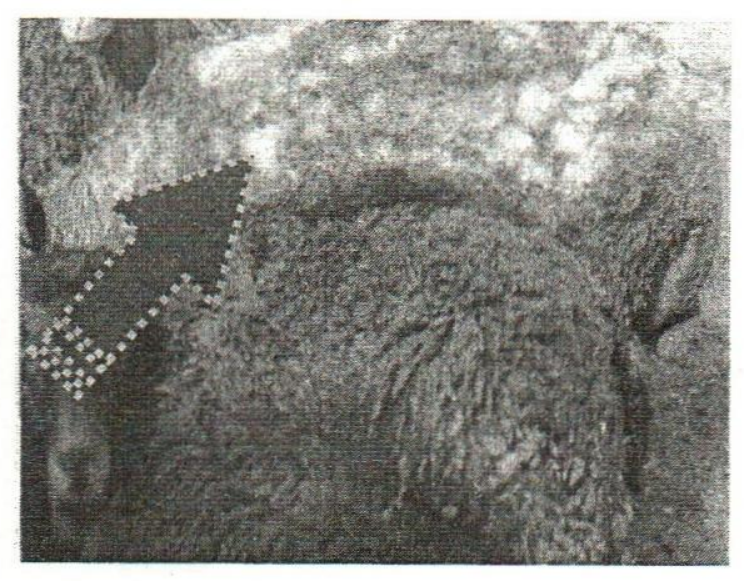

Fig. 2: Close up on the lesion revealing wrinkled skin, broken and matted wool .

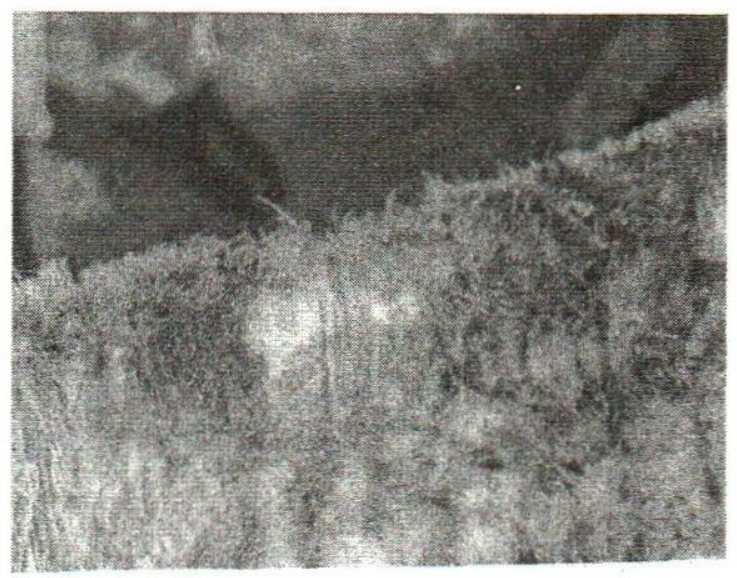


Fig. 3: The lesion of dermatophilosis in the face and ears of ewe.

Fig. 4: The lesions of dermatophilosis not confined on the head region but involve the legs of a lamb.
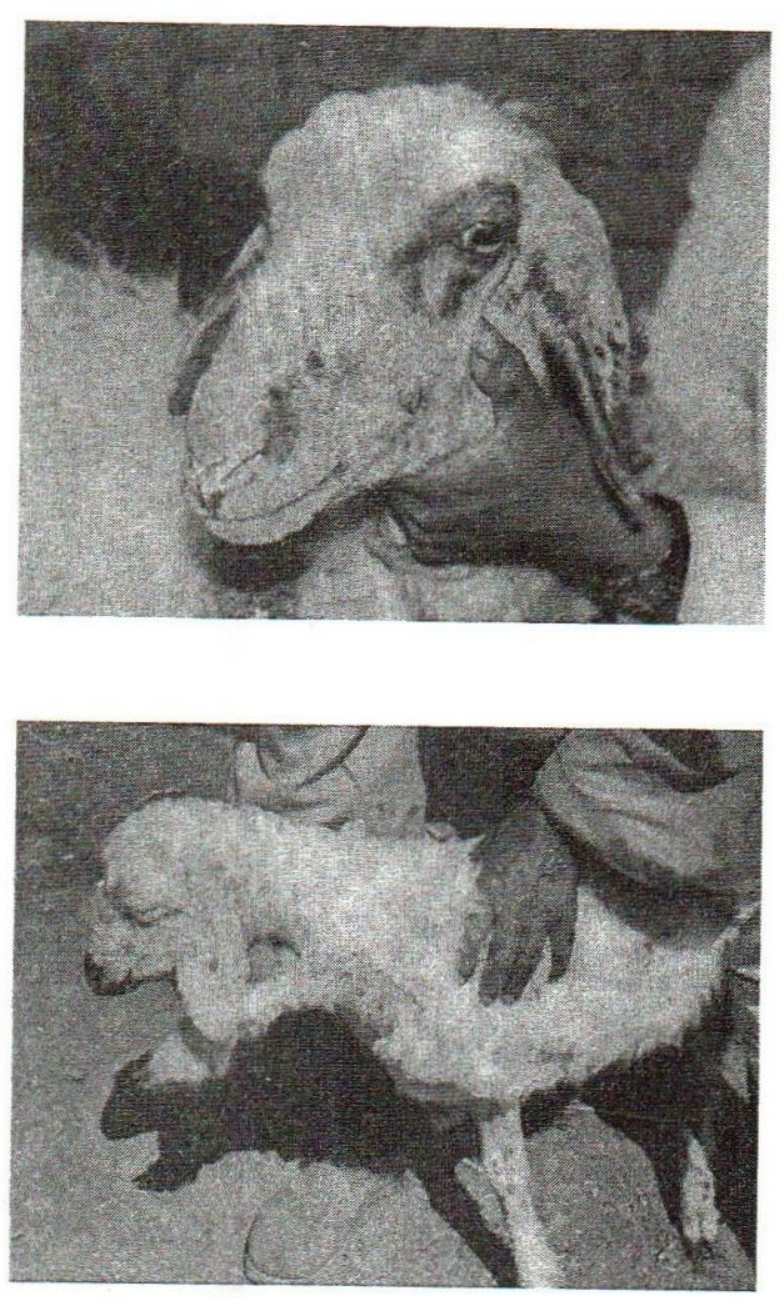

Fig. 5: A goat showing lesions of dermatophilosis in the skin of chest and abdomen .

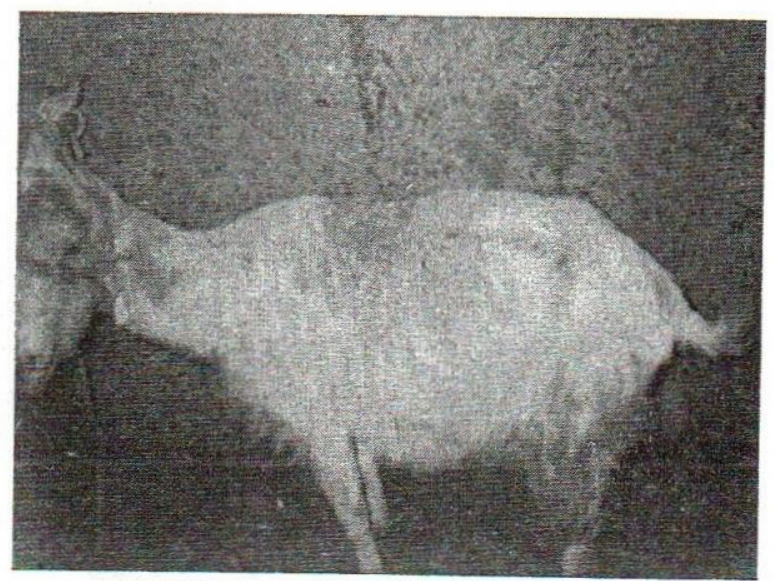


Fig. 6: The lesion of dermatophilosis in buffaloes is confined on the distal of portion of the legs.

Fig. 7: Crusty lesions of dermatophilosis on the back region of a cow.

Fig. 8: Extensive lesions of dermatophilosis on the back of a cow.
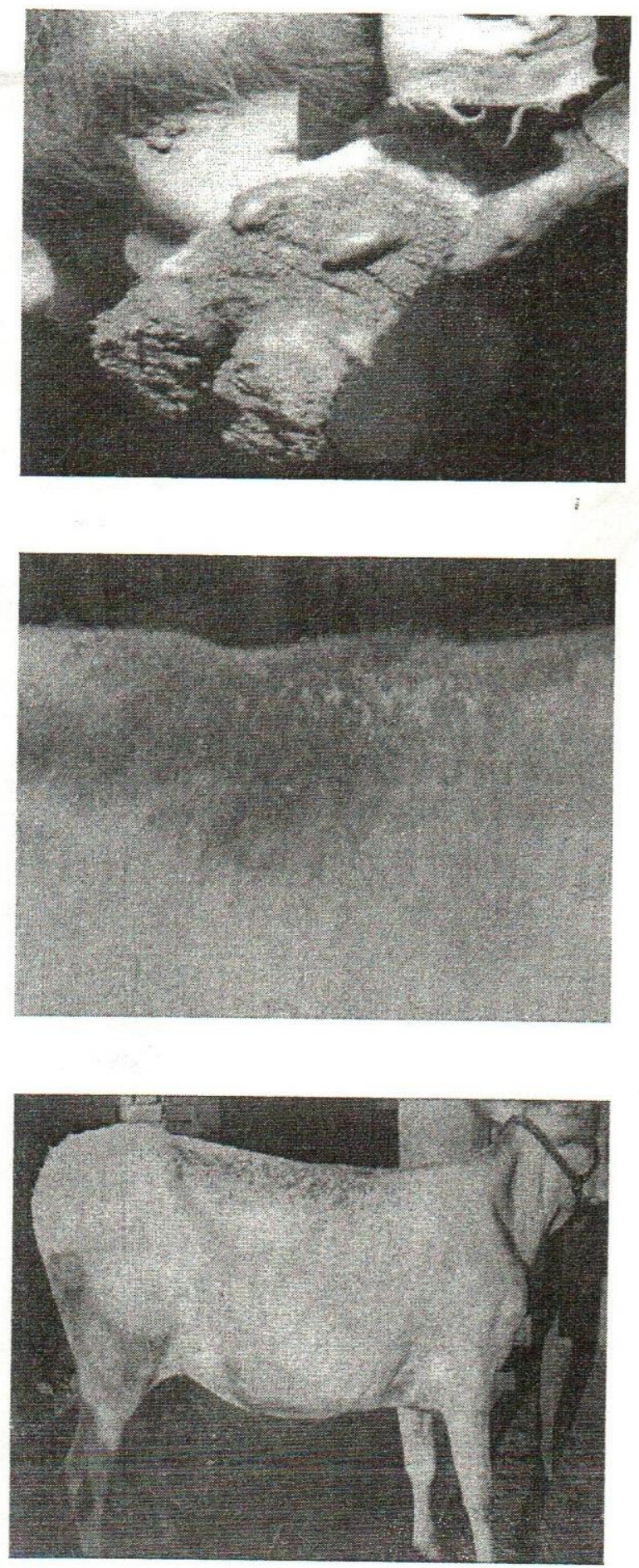
Fig. 9: Exudative severe dermatitis on the skin of the chest and abdomen caused by $\mathrm{D}$. congolensis.

Fig. 10: Close up on the lesion revealing the alopecia, crusts and matted hair.
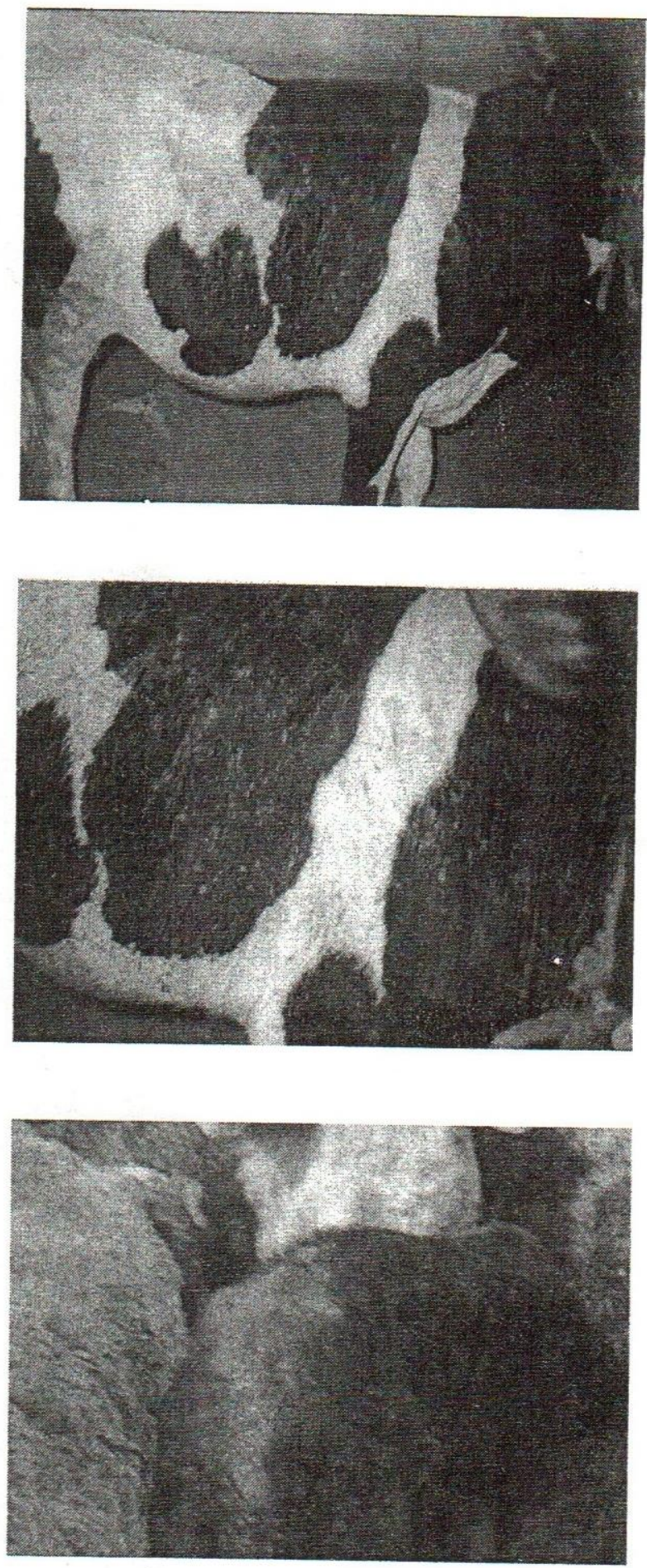

Fig. 11: The lesions of dermatophilosis appeared on the back and tail region. 
Fig. 12: The lesion begin to improve after treatment.

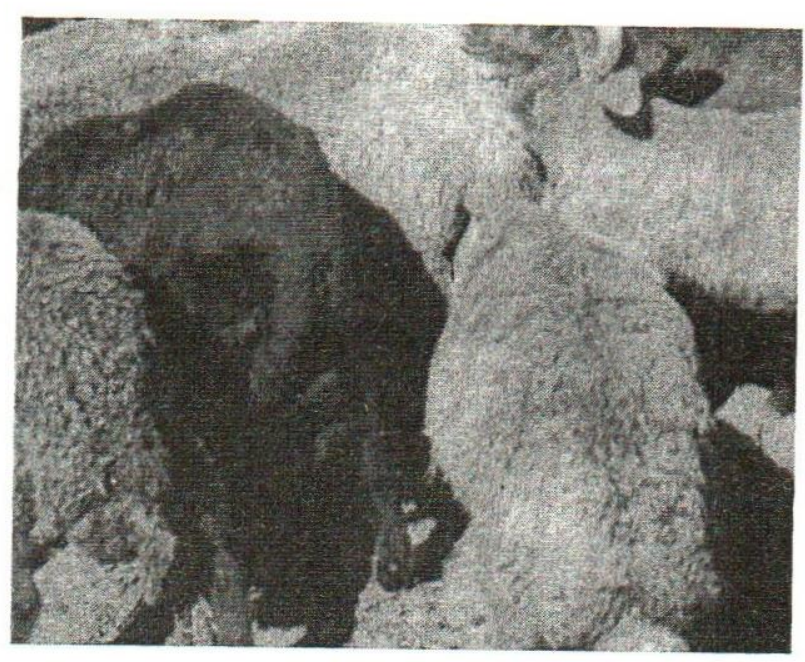

\section{DISCUSSION}

Dermatophilosis is a skin disease caused by Dermatophilus congolensis. It has a world wide distribution and a wide-host range including man. Concerning the clinical picture, it was found that in spite of the similarity of the developing lesions, it was varied in its distribution in different animal species. In sheep and goats the lesions were prominent on the head region (face and ears) as wells the legs from the coronets to the knees, and also on the back and tail region. In cattle, the lesion were confined on the chest and abdomen while in buffaloes the lesions were restricted on the distal portions of the legs. The variation of distribution of the lesions may attributed to the effect of the predisposing factors; legs and face regions of sheep were mostly exposed to fleas infestation with subsequent exposure to dermatophilosis. The lesions on the back, chest and abdominal regions may related to moisture which accumulate and retained by the long hair or fleece specially during the rainy season. In buffaloes, the restriction of lesions on the distal portion of the legs may related to the wet soil and muddy environment that preferred by buffaloes. Within the same species, the lesions varied in its severity and nature in relation to the site of infection; It was crusty in the face and edges of the ears while, in areas with long hair or wool, it appeared as exudative dermatitis with broken and matted hair or fleece. These results and assumptions agree with those of Hagan and Burner (1992); Zaria (1993), Higgins and write (1998), Dwight and Yuan (1999), Abdel-Halim et al. (2000) and Ammar (2003). 
Regarding the treatment of dermatophilisis, it was found that the topical treatment with garlic oil is more efficient than the parentral one using long acting oxytetracycline. This may explained as the direct and continuous contact of the topically applied garlic oil leads to softening of the crusts inducing falling off them with inhibition of development of Dermatophilius conglensis. On the other side, with parentral treatment some crusts could remain and the rough borders of the damaged skin did not completely disappear. Then, dermatophilus conglensis which can persist in such areas, start to develop again resulting in recurrence of signs after clinical cure of some cases. These results and explanation agree with those of Lloyd and Noble, (1982), Wilson and Amakiri (1989) Lloyd et al., 1990 and Ali - Emmanuel et al., (2003). The high efficacy of garlic oil is in accordance with the in vitro trails of Elisah (2004).

\section{REFERENCES}

Abdel-Halim, M.M., Abdel-Samee, A.A. and El-Sayed, M.M. (2000): Dermatophilosis in Egyptian buffaloes: clinical study, diagnosis and treatment. Ninth sci cong. 2000. Fac. Vet. Medicine, Assiut, Egypt PP. 336 - 345.

Ali Emmanuel, N.; Moudachirou, M.; Akakpo, J.A. and Quetin Leclercq, J. (2003): Treatment of bovine dermatophilosis with Senna alata, Lantana camera and Mitracarpus scaber leaf extracts. Journal of Ethnopharmacology 86, 167 - 171.

Ammar, K.M. (2003): Dermatophilosis among sheep and goats in Menofia governorate - Egypt. $7^{\text {th }}$ sci cong. Egyptian society for cattle diseases. 7-9 Dec. 2003, Assiut, Egypt. PP. 99- 111.

Dean, J.D.; Gordon, M.A.; Charles, W.; Severinghans, C.H.; Kroll, ET. and Reilly, JR. (1961): Streptothricosis: a new zoonotic disease. New Yourk stat. J. Med. 1961: 1283.

Dwight C. Hirsh and Yuan Chung Zee (1999): Vet. Microbiology, Blackwell science, Inc.

Elisha Yardley (2004): preliminary study investigating the effect of the application of some essential oils on the in vitro proliferation of Dermatophilus conglensis. The international Journal of Aromatherapy (2004) 14, 129 -135.

Hagan, W. and Burner, D. (1992): Hagan and Burner's microbiology and infectious diseases of domestic animals. $8^{\text {th }}$ ed. London: Cornell Univ. press. 
Higgins, A.J. and Wright, I.M. (1998): The equine manual. UK: WB Saunders Co. Ltd.

Ilemobad, A.A.; Gyang, E.O.; Bida, S.A. and Oddo, P.B. (1979): Cure of Dermatophilus conglensis infection in cattle by long acting oxytetracycline. Review of veterinary science $27,302-305$.

Kelly, W.R. (1984): Veterinary clinical Diagnosis $3^{\text {rd }}$ ed. Bailliers, Tindall, London, U K.

Lloyd, D.H. and Noble, W.C. (1982): Interaction between antibiotic producing bacteria and $D$. congolensis. a potential therapeutic tool. In. Woodbine, M (Ed.), Antimicrobial agents and agriculture. Butterworths, London PP. 277-283.

Lloyd, D.H.; Hawkins, J.P. and Pragnell, J. (1990): Efficacy of long acting oxytetracyclne in treatment and control of bovine dermatophilsis. Vet. Dermatology 1. $79-84$.

Quinn, P.J.; Carter, M.F.; Markey, B.K. and Caster, G.R. (1994): Clinical Vet. Microbiology $1^{\text {st }}$ ed. Mosby. Year Book.

Sutherlands, S.S.; Ellis, T.M.; Edwards, J.R. (1991): Evaluation of vaccines against ovine dermatophilosis. Vet. Microbiology, 27, $91-99$.

Wilson, O.B. and Amakiri, S.F. (1989): Chemotherapy of dermatophilosis in a herd of Fulani cattle. Bulletin of Animal Health and production in Africa. 37, 315 - 317.

Yeruham I.; Hadani A. and Elad, D. (1991): Human Dermatophilosis (Dermatophilis congdensis) in dairy men in Israel. Isr. Jour. Vet. Medicine 1991, 46: 114.

Zaria, LT. (1993): Dermatophils congolensis infection (Dermatophilosis) in animals and man. An up date. Comp. Immun. microbiol. Infect Dis. 16 (3) 179 -222. 